\title{
龙血竭抑制大鼠脊髓背角广动力范围神经元诱发 放电的药效物质
}

\author{
郭敏，陈素，刘向明* \\ 中南民族大学生物医学工程系, 武汉 430074 \\ * 联系人, E-mail: liu.xiangming@263.net
}

收稿日期: 2008-03-03; 接受日期: 2008-07-24

国家民委自然科学基金(批准号: MZY06002)资助项目

\begin{abstract}
摘要通过在体动物实验, 在整体水平上确证龙血竭的镇痛效应及产生此效应的 药效物质. 对完整 Wistar 雄性大鼠模型, 采用细胞外微电极记录技术, 观察龙血竭及 其化学成分剑叶龙血素 A、剑叶龙血素 B、龙血素 B, 以及这 3 种成分的各种组合对 电刺激坐骨神经诱发的脊髓背角广动力范围神经元放电活动的影响. 应用等效剂量 概念, 在药物量效关系曲线 Hill 系数相异的情况下, 导出了判定 3 种药物相互作用性 质的相加等效曲面方程. 基于这些方程和 Tallarida 所建立的判定具有不相似量效曲 线的 2 种药物相互作用性质的等效线方程, 确定 3 种成分在不同的组合方式下调制广 动力范围神经元诱发放电活动时的相互作用性质. 结果表明, 龙血竭及其 3 种成分均 对广动力范围神经元的诱发放电频率具有浓度依赖的抑制作用, 但描述 3 种成分量 效关系曲线的 Hill 系数各不相同. 各种组合中只有剑叶龙血素 A、剑叶龙血素 B 和 龙血素 B 的组合能够产生与龙血竭类似的抑制效应，且这 3 种成分在联合抑制广动 力范围神经元的诱发放电频率时具有协同作用. 上述结果说明, 龙血竭能通过 3 种成 分的相互作用在脊髓水平干预痛觉信息的传导和加工, 进一步证实了其镇痛效应的 药效物质是这 3 种成分的分子组合.
\end{abstract}

\section{关键词}

龙血竭

药效物质

细胞外微电极记录

广动力范围神经元

药物相互作用
龙血竭是传统药物中的一味名贵药材, 是多种 成分的混合物, 具有行瘀止痛、止血敛疮等功效, 有 “活血圣药”之称. 其药理学实验、临床疗效观察以及 毒理学实验的结果 ${ }^{[1,2]}$, 说明龙血竭中产生镇痛效应 的化学成分具有开发成一种安全有效、成瘾性低的新 型镇痛药物的潜能. 本实验室曾以百合科龙血树属 (Dracaena) 植物剑叶龙血树(Dracaena cochinchinensis (Lour.) S.C.Chen)含脂木材中提取的龙血竭为实验对 象, 应用膜片钳实验技术, 观察到其对与疼痛发生和 传导机制关系密切的背根神经节(dorsal root ganglion, DRG) 细胞河豚毒素敏感型 (tetrodotoxin-sensitive, TTX-S) 和河豚毒素不敏感型 (tetrodotoxin-resistant, TTX-R)钠离子通道电流具有调节作用 ${ }^{[3,4]}$, 提出了龙 血竭可能通过直接干预外周痛觉信息的传导过程来 发挥其镇痛效应的机制. 以龙血竭本身对 TTX-S 和 TTX-R钠离子通道电流的调节作用作为参照, 比较 了龙血竭和其 3 种化学成分剑叶龙血素A、剑叶龙血 素 $\mathrm{B}$ 和龙血素 $\mathrm{B}$ 的各种组合的药理效应参数, 所得结 
果提示龙血竭 3 种化学成分的分子组合是龙血竭调 节DRG细胞 TTX-S 和 TTX-R钠离子通道电流的药效 物质 ${ }^{[4]}$.

在疼痛的传导路径中, DRG和脊髓背角(spinal dorsal horn, SDH) 是痛觉传递的两个重要起始部位. 外周的伤害性刺激传入经DRG的中枢轴突可直接传 至SDH神经元，通过脊髓丘脑束等神经纤维束传至 丘脑再至大脑皮层产生痛觉; 组织损伤导致的长时 间 SDH神经元功能的改变, 又可以反过来影响DRG 神经元对疼痛的反应. 从二者之间的相互关系推测, 龙血竭既然能调制离体DRG细胞电压门控性钠离子 通道电流，应该也能影响在体SDH神经元的放电活 动. 以往对龙血竭的药理实验并未涉及药物进入机 体后到达靶细胞的过程，药物在机体内发挥作用的 过程又比较复杂, 所以有必要设计在体动物实验, 观 察龙血竭通过机体内部复杂的整合、调节后对SDH放 电活动的影响, 在整体动物水平上对其干预痛觉信 息传导，产生镇痛效应的药效物质进行更深入的药 效学研究. 在SDH中对痛觉信息的传导、整合以及痛 觉强度的分辨起重要作用的神经元主要是非特异性 广动力范围(wide dynamic range, WDR)神经元 ${ }^{[5]}$. 本 研究以乌拉坦麻醉下的在体大鼠为实验对象, 采用 细胞外微电极记录的方法, 观察龙血竭、其化学成分 剑叶龙血素A、剑叶龙血素B、龙血素B以及这 3 种成 分的各种组合对电刺激坐骨神经诱发的WDR 神经元 放电活动的影响, 并对化学成分之间是否存在药效 学相互作用进行评估.

\section{1 材料与方法}

\section{1 实验药品的配制}

龙血竭、剑叶龙血素 $\mathrm{A}$ 、剑叶龙血素 $\mathrm{B}$ 和龙血 素 B 均购自广西中医药研究所, 龙血竭为百合科龙血 树属植物剑叶龙血树 (Dracaena cochinchinensis (Lour.) S. C. Chen.)含脂木材中提取的醇提物，龙血. 竭及其 3 种化学成分由卢文杰教授提取、分离、鉴定.
3 种化学成分的纯度均为 $98 \%$, 从龙血竭中提取分离 出的剑叶龙血素 A、剑叶龙血素 B 和龙血素 B 分别 占提取终产物的 $22 \%, 11 \%$ 和 $5 \%$.

所有药品均用人工脑脊液(artificial cerebrospinal fluid, ACSF)配制, 其成分为: $\mathrm{NaCl} 115.0 \mathrm{mmol} / \mathrm{L}, \mathrm{KCl}$ $5.6 \mathrm{mmol} / \mathrm{L}, \mathrm{CaCl}_{2} 2.0 \mathrm{mmol} / \mathrm{L}, \mathrm{MgCl}_{2} 1.0 \mathrm{mmol} / \mathrm{L}$, glucose $11.0 \mathrm{mmol} / \mathrm{L}, \mathrm{NaH}_{2} \mathrm{PO}_{4} 1.0 \mathrm{mmol} / \mathrm{L}, \mathrm{NaHCO}_{3}$ $25.0 \mathrm{mmol} / \mathrm{L}$, 用 $1 \mathrm{~mol} / \mathrm{L} \mathrm{HCl}$ 调 $\mathrm{pH}$ 值至 7.4, 渗透压 至 $300 \mathrm{mOsm} / \mathrm{L}$, 上述所有化学试剂均为国产分析纯.

本实验以 $0.05 \%$ 龙血竭溶液 ${ }^{[4]}$ 影响WDR神经元 诱发放电活动的药理效应作为比较龙血竭的药理效 应和其化学成分(组合)的药理效应的标准. 另配制 $0.005 \%, 0.0005 \%, 2 \%$ 和 $5 \% 4$ 种浓度的龙血竭溶液， 分别观察它们的药理效应，据此确定龙血竭药理效 应的浓度依赖性.

剑叶龙血素 A、剑叶龙血素 B 和龙血素 B 这 3 种单体化学成分的溶液浓度以及它们各种组合的溶 液浓度，均按照它们各自在龙血竭提取终产物中的 百分比含量设定，从而确保各种单体化学成分的溶 液和化学成分组合的溶液中所含的各种化学成分与 $0.05 \%$ 的龙血竭溶液中所含的各种化学成分在含量和 质量比例关系上的一致。单体化学成分溶液的配制 见表 1 , 化学成分组合溶液的配制见表 2 .

\section{2 细胞外微电极记录}

(1) 动物手术. 实验采用 3 4 月龄的雄性 Wistar 大鼠(体重 250 300 g, 武汉大学实验动物中心提供). 大鼠用乌拉坦 $(1.2 \mathrm{~g} / \mathrm{kg})$ 腹腔麻醉后行气管插管术和 尾静脉插管术. 术后将大鼠移至立体定位架上，俯位 固定脊柱 $\mathrm{T} 11$ 与 $\mathrm{L} 3$ 段, 于腰膨大处切开皮肤，使用 雉板切除术暴露脊髓 T13 L1 节段; 并在左侧后肢股 部切开皮肤，游离坐骨神经约 $1 \mathrm{~cm}$ 置于刺激电极上; 将脊髓周围的皮肤及神经周围的皮肤缝制成 2 个浴 槽，并在浴槽内滴加 $38^{\circ} \mathrm{C}$ 的液体石蜡，以防止脊髓和

\section{表 1 单体化学成分的溶液}

\begin{tabular}{lccc}
\hline 单体化学成分 & 与 $0.05 \%$ 龙血竭溶液浓度相对应的溶液浓度 $/ \mathrm{mmol} \cdot \mathrm{L}^{-1}$ & 为计算浓度依赖性所添加的溶液浓度 $/ \mathrm{mmol} \cdot \mathrm{L}^{-1}$ \\
\hline 剑叶龙血素 A & $0.38(0.011 \%)$ & 0.19 & 0.76 \\
剑叶龙血素 B & $0.19(0.0055 \%)$ & 0.38 & 0.76 \\
龙血素 B & $0.08(0.0025 \%)$ & 0.008 & 0.8 \\
\hline
\end{tabular}


表 2 化学成分组合的溶液

\begin{tabular}{cccc}
\hline 化学成 & \multicolumn{3}{c}{ 所含化学成分浓度 $/ \mathrm{mmol} \cdot \mathrm{L}^{-1}$} \\
\cline { 2 - 4 } 分组合 & 剑叶龙血素 $\mathrm{A}$ & 剑叶龙血素 B & 龙血素 B \\
\hline 组合 1 & 0.38 & 0.19 & 0 \\
组合 2 & 0.38 & 0 & 0.08 \\
组合 3 & 0 & 0.19 & 0.08 \\
组合 4 & 0.38 & 0.19 & 0.08 \\
\hline
\end{tabular}

坐骨神经干燥. 术后静脉推注肌肉松弛剂三碘季铵 酚(首量: $100 \mathrm{mg} / \mathrm{kg}$, 维持量: $30 \mathrm{mg} / \mathrm{kg}$, 每隔 $30 \mathrm{~min}$ 注射 1 次)制动，并上动物呼吸机行人工呼吸(频率: 90 次 $/ \mathrm{min}$; 吸呼比: $1: 2$; 潮气量: $5 \sim 6 \mathrm{~mL}$ ), 同时将 大鼠置于 $37^{\circ} \mathrm{C}$ 恒温毯上, 维持大鼠体温于正常生理 水平 $\left(\right.$ 直肠温度 $\left.(37 \pm 1)^{\circ} \mathrm{C}\right)$, 并调整大鼠胸廓的位置以 减少脊髓随大鼠的呼吸运动而产生的移动. 实验过 程中随时观察动物瞳孔大小、角膜反射和皮肤色泽， 若上述生理指标异常则立即终止实验.

(2) WDR神经元的判定. 在大鼠所暴露的坐骨神 经同侧的脊髓 $\mathrm{T} 13 \sim \mathrm{L} 1$ 节段, 距脊髓前正中动脉旁 $0.5 \sim 1 \mathrm{~mm}$ 处, 应用微电极推进器将充灌 $0.5 \mathrm{~mol} / \mathrm{L}$ 醋 酸钠溶液, 电极阻抗在 $5 \sim 12 \mathrm{M} \Omega$ 范围的玻璃微电极 尖端缓慢垂直地插入此处的脊髓背角，插入深度控 制在 70 1300 $\mu \mathrm{m}$ 范围内. 在微电极推进的过程中, 经刺激电极持续向大鼠的坐骨神经施以强度为 $4 \sim 5 \mathrm{~V}$, 波宽为 $3 \mathrm{~ms}$, 频率为 $1 \mathrm{~Hz}$ 的方波刺激, 同时采用 BL-420E生物机能实验系统对玻璃微电极引入的电 信号进行采样，一旦监测到电刺激坐骨神经诱发的 $\mathrm{SDH}$ 神经元的放电活动, 即刻停止电刺激和电极的 推进，并在暴露的大鼠坐骨神经同侧后爪上确定其 皮肤感受野, 于感受野内分别施以非伤害性刺激(用 毛刷刷)和伤害性刺激(用镊子捏)，如果 2 种刺激均能 引起神经元放电频率增高, 且伤害性刺激所引起的 放电频率明显高于非伤害性刺激，则产生诱发放电 的 SDH神经元为WDR 神经元 ${ }^{[6,7]}$.

(3) 实验步骤. 待 WDR 神经元放电活动稳定后, 再经刺激电极向大鼠的坐骨神经施以一次强度为 4 $5 \mathrm{~V}$, 波宽为 $3 \mathrm{~ms}$, 频率为 $1 \mathrm{~Hz}$, 串长为 $20 \mathrm{~s}$ 的方波串 刺激，以该伤害性电刺激施加的时刻为始点，记录 30 $\mathrm{s}$ 的 WDR 神经元的诱发放电活动作为空白对照. 然 后, 用加样枪向玻璃微电极插入处的脊髓表面垂直
滴加 $10 \mu \mathrm{L}$ 的药品溶液, 并在加药后 $2,5,10,15,20$, $25,30 \mathrm{~min}$ 时刻均施加一次上述脉冲串刺激, 从加药 时刻起一直观察并记录 WDR 神经元的放电信号, 30 $\min$ 后方可结束记录. 一次记录完成后, 用人工脑脊 液将脊髓表面的残余药液冲洗干净，静息至少 30 $\min$ 后，再开始寻找下一个 WDR 神经元.

\section{3 数据分析}

WDR 神经元每秒的诱发放电个数, 即放电频率, 可由 BL-420E 生物机能实验系统自动统计出来. 为 了比较 WDR 神经元诱发放电频率在加药前后的时间 分布特征, 可绘制以每次脉冲串刺激施加时刻为始 点的 $30 \mathrm{~s}$ 内的诱发放电频率直方图. 直方图的纵坐标 为 WDR 神经元的放电频率，直方图中每个矩形的宽 度为 $1 \mathrm{~s}$. 以每次脉冲串刺激施加时刻为始点的 $30 \mathrm{~s}$ 内的 WDR 神经元的平均放电频率作为反映其诱发放 电活动强弱的指标. 统计加药前 $2 \mathrm{~min}$ 施加方波串刺 激 WDR 神经元 $30 \mathrm{~s}$ 内的平均放电频率 $f_{\text {control }}$ 并作为 空白对照, 再统计加药后 2, 5, 10, 15, 20, 25, $30 \mathrm{~min}$ 时刻施加方波串刺激 WDR 神经元 $30 \mathrm{~s}$ 内的平均放电 频率 $f_{2}, f_{5}, f_{10}, f_{15}, f_{20}, f_{25}, f_{30}$. 所有实验数据采用 SPSS 统计软件包进行处理, 对单因素影响的数据进 行 $t$ 检验, 对双因素(第一因素即处理因素为药物, 第 二因素为时间)影响的数据采用双因素 ANOVA 检验 以排除时间因素对检验结果的干扰，以 $P<0.05$ 作为

显著性检验的标准. 所有的数据均用 $\bar{x} \pm \mathrm{SE}$ 表示.

药物对 WDR 神经元诱发放电频率的抑制率 (Inhibition\%)用以下公式计算,

$$
\text { Inhibition } \%=\frac{f_{\text {control }}-f_{\text {drug }}}{f_{\text {control }}} \times 100 \%,
$$

其中 $f_{\text {drug }}$ 为加药后 WDR 神经元的诱发放电频率.

药物的浓度依赖性曲线用 Hill 方程拟合,

$$
\frac{\text { Inhibition\% }}{\text { Inhibition }_{\max } \%}=\frac{1}{1+\left(\frac{\mathrm{IC}_{50}}{c}\right)^{h}},
$$

其中 Inhibition\% 为药物对 WDR 神经元诱发放电频率 的抑制率, Inhibition max $_{\text {m }}$ 为最大抑制率, $\mathrm{IC}_{50}$ 为药物 的半数抑制浓度, $c$ 为药物的浓度, $h$ 为 Hill 系数. 


\section{4 化学成分之间药效学相互作用的评估}

药效学相互作用是指同时或相继使用 2 种或 2 种以上药物时，其中一种药物作用的大小、持续时间 甚至性质受其他药物的影响而发生明显改变. 根据 各组成药物的量效关系曲线可建立零相互作用的相 加等效线(曲面)方程，来判定药物间药效学相互作用 的性质. 药物间的相互作用可被定性为 3 种情况：即 相加、协同和拮抗 ${ }^{[8]}$, 分别指药物的实际合用效应等 于、大于以及小于药物之间相互作用为零时的合用效 应.

当 2 种药物 $\mathrm{A}, \mathrm{B}$ 单独作用所能产生的最大效应 $\left(E_{\max }\right)$ 相同，且描述它们量效关系曲线的Hill系数也 相同时, $\mathrm{A}$ 与 $\mathrm{B}$ 的效价强度比(药物产生相同的效应时 所需要的剂量之比)是定常的, 在这种情形下, 基于 Loewe与 Muischnek的等效剂量概念 ${ }^{[9]}$, 表明零相互 作用的相加等效线方程是：

$$
\frac{a}{A_{i}}+\frac{b}{B_{i}}=1
$$

其中 $A_{i}$ 和 $B_{i}$ 分别表示药物 $\mathrm{A}, \mathrm{B}$ 单独作用产生效应 $E_{i}$ $\left(0<E_{i}<E_{\text {max }}\right)$ 各自所需的剂量, $a$ 和 $b$ 则分别表示药物 $\mathrm{A}, \mathrm{B}$ 联合作用产生效应 $E_{i}$ 各自所需的剂量. 方程(3) 的左边被称为相互作用指标，通过计算相互作用指 标或进行等效图分析(isobologramic analysis)可确定 相互作用的性质.

当 2 种药物 $\mathrm{A}$ 和 $\mathrm{B}$ 所能产生的最大效应 $\left(E_{\max }\right)$ 相同, 但描述它们量效关系曲线的Hill系数相异时, $\mathrm{A}$ 与 $\mathrm{B}$ 的 效价强度比是非定常的, 并且由于 2 种药物均能获得 同一最大效应，使药物 $\mathrm{A} 、 \mathrm{~B}$ 彼此间究竟是谁对谁的效 应做出贡献无法区分，相加等效线不止一条. Tallari$\mathrm{da}^{[10,11]}$ 基于等效剂量概念推导了围成零相互作用区 域且相对于点 $\left(\frac{A_{i}}{2}, \frac{B_{i}}{2}\right)$ 对称的 2 条相加等效线(图 1(A))的方程:

$$
\begin{aligned}
& b=B_{50}\left(\frac{A_{i}-a}{A_{50}}\right)^{\frac{h_{A}}{h_{B}}}, \\
& b=B_{i}-\frac{B_{50}}{\left(\frac{A_{50}}{a}\right)^{\frac{h_{A}}{h_{B}}}},
\end{aligned}
$$

其中 $A_{i}, B_{i}, a, b$ 表示的意义与方程(3)中参数的意义相 同, $A_{50}$ 和 $B_{50}$ 分别表示药物 $\mathrm{A}$ 和药物 $\mathrm{B}$ 单独作用产生 效应 $E_{\max } / 2$ 各自所需的剂量, $h_{A}$ 和 $h_{B}$ 分别表示描述药 物 A, B 量效关系曲线的 Hill 系数, 公式(4)中剂量为 $b$ 的药物 $\mathrm{B}$ 与剂量为 $\left(A_{i}-a\right)$ 的药物 $\mathrm{A}$ 等效, 公式(5)中 剂量为 $a$ 的药物 $\mathrm{A}$ 与剂量为 $\left(B_{i}-b\right)$ 的药物 $\mathrm{B}$ 等效.

当 3 种化学成分所能产生的最大效应 $\left(E_{\max }\right)$ 相同, 而描述药物量效关系曲线的 Hill 系数不同时, 药物 $\mathrm{A}, \mathrm{B}, \mathrm{C}$ 中究竟是谁起主导作用仍然无法确定，因而 基于等效剂量概念推导了 3 种药物联合作用产生效 应 $E_{i}$ 的 3 个相加等效曲面(图 1B)的方程:

$$
c=C_{i}-\frac{C_{50}}{\left(\frac{A_{50}}{a}\right)^{\frac{h_{A}}{h_{C}}}}-\frac{C_{50}}{\left(\frac{B_{50}}{b}\right)^{\frac{h_{B}}{h_{C}}}},
$$

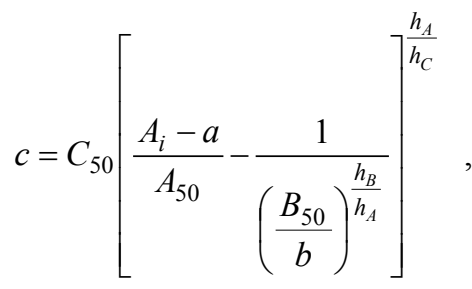

$$
c=C_{50}\left[\frac{B_{i}-b}{B_{50}}-\frac{1}{\left(\frac{A_{50}}{a}\right)^{\frac{h_{A}}{h_{B}}}}\right]^{\frac{h_{B}}{h_{C}}},
$$

其中 $A_{i}, B_{i}, A_{50}, B_{50}, h_{A}, h_{B}$ 参数的意义与公式(4), (5)中 各参数的意义相同, $a, b, c$ 则分别表示药物 $\mathrm{A}, \mathrm{B}, \mathrm{C}$ 联 合作用产生效应 $E_{i}$ 各自所需的剂量, $C_{i}, C_{50}$ 分别表示 药物 $\mathrm{C}$ 单独作用产生效应 $E_{i}$ 和 $E_{\max } / 2$ 所需的剂量, $h_{C}$ 表示描述药物 $\mathrm{C}$ 量效关系曲线的 Hill 系数, 公式(6) 中剂量为 $a$ 的药物 $\mathrm{A}$ 和剂量为 $b$ 的药物 $\mathrm{B}$ 的组合与 剂量为 $\left(C_{i}-c\right)$ 的药物 $\mathrm{C}$ 等效, 公式(7)中剂量为 $b$ 的药 物 $\mathrm{B}$ 和剂量为 $c$ 的药物 $\mathrm{C}$ 的组合与剂量为 $\left(A_{i}-a\right)$ 的药 物 $\mathrm{A}$ 等效, 公式(8)中剂量为 $a$ 的药物 $\mathrm{A}$ 和剂量为 $c$ 的药物 $\mathrm{C}$ 的组合与剂量为 $\left(B_{i}-b\right)$ 的药物 $\mathrm{B}$ 等效.

根据等效图解法判定 2 种或 3 种药物相互作用性 质的具体方法如下:

当剂量为 $a^{\prime}$ 的药物 $\mathrm{A}$ 和剂量为 $b^{\prime}$ 的药物 $\mathrm{B}$ 联合 作用产生效应 $E$ 时, 若需判定药物 $\mathrm{A}, \mathrm{B}$ 之间的相互 
作用性质，则根据药物 $\mathrm{A}, \mathrm{B}$ 的量效关系曲线，可绘制 药物 $\mathrm{A}, \mathrm{B}$ 联合作用产生效应 $E$ 的相加等效线, 以 $a^{\prime}$, $b^{\prime}$ 为坐标描出实验点 $\mathrm{Q}($ 图 1(A)), $\mathrm{Q}$ 点在 2 条等效线之 下、之上或之间，则认为药物 A, B 之间相互作用的性 质分别为协同、拮抗或相加.

当剂量为 $a^{\prime}$ 的药物 $\mathrm{A}$ 、剂量为 $b^{\prime}$ 的药物 $\mathrm{B}$ 和剂 量为 $c^{\prime}$ 的药物 $\mathrm{C}$ 联合作用产生效应 $E$ 时, 若需判定药 物 $\mathrm{A}, \mathrm{B}, \mathrm{C}$ 之间的相互作用性质，则根据药物 $\mathrm{A}, \mathrm{B}, \mathrm{C}$ 的量效关系曲线，可绘制药物 $\mathrm{A}, \mathrm{B}, \mathrm{C}$ 联合作用产生 效应 $E$ 的相加等效曲面, 以 $a^{\prime}, b^{\prime}, c^{\prime}$ 为坐标描出实验 点 $\mathrm{Q}$ (图 1(B)), $\mathrm{Q}$ 点在所有等效曲面之下或之上，则认 为药物 $\mathrm{A}, \mathrm{B}, \mathrm{C}$ 之间相互作用的性质分别为协同或拮 抗；其他情况，则认为药物 $\mathrm{A}, \mathrm{B}, \mathrm{C}$ 之间相互作用的 性质为相加.

应用 Matlab 和 SPSS 软件完成上述等效线图解法 分析过程. 为了从统计学上确定实验点 $\mathrm{Q}$ 与等效线、 等效曲面的位置关系, 将点 $\mathrm{Q}$ 的坐标值与其所对应 的理论可加点(由原点发出的经过点 $\mathrm{Q}$ 的射线与等效 线或等效曲面的交点, 在二维坐标图上射线与 2 条等 效线相交形成的理论可加点为 2 个, 此时这条射线对 应着药物 A, B 之间的固定剂量比; 在三维坐标图上 射线与 3 个等效曲面相交形成的理论可加点为 3 个, 此时这条射线对应着药物 A, B, C 之间的固定剂量比)

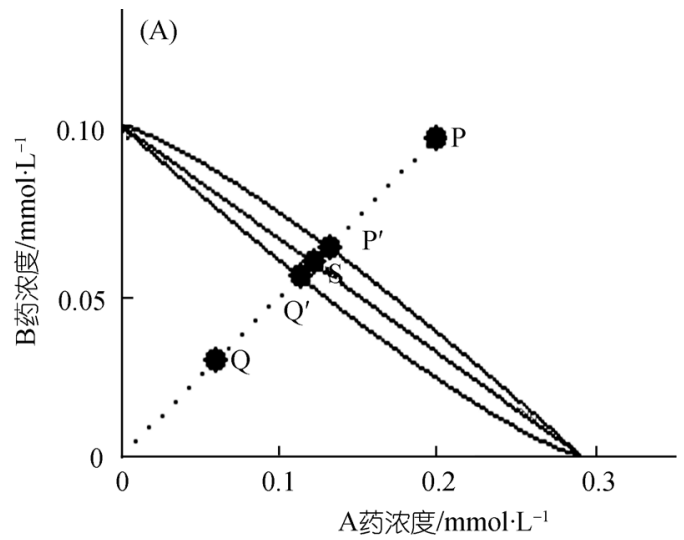

的相应坐标值进行统计比较. 如果点 $\mathrm{Q}$ 的坐标值小 于其所对应的理论可加点的相应坐标值的最小值且 不在其 $95 \%$ 置信区间内则认为 $Q$ 点在所有等效线(曲 面)之下; 如果点 $\mathrm{Q}$ 的坐标值大于其所对应的理论可 加点的相应坐标值的最大值且不在其 $95 \%$ 置信区间 内则认为 $\mathrm{Q}$ 点在所有等效线(曲面)之上; 其他情况, 则认为 $Q$ 点在等效线(曲面)之间.

\section{2 结果}

\section{1 龙血竭对电刺激坐骨神经诱发的 WDR 神经 元放电频率的影响}

所记录的 136 个WDR神经元的诱发放电活动均 具有短时程的早成分放电一一无放电的宁静期一一长 潜伏期的晚成分放电的典型 “两串” 反应形式 ${ }^{[12]}$. 实 验以 ACSF作为阴性对照药品, 观察了滴加 ACSF至 脊髓表面对电刺激坐骨神经诱发的WDR神经元放电 频率的影响. 以加入ACSF前WDR 神经元的诱发放电 频率为自身对照, 进行 $t$ 检验。结果表明，在滴加 ACSF后的 2, 5, 10, 15, 20, 25, $30 \mathrm{~min}$ 时刻, WDR 神经 元的诱发放电频率没有改变 $(n=6, P>0.05)$. 滴加不同 浓度的龙血竭溶液至脊髓表面, 于加药后 $2 \mathrm{~min}$ 即可 观察到WDR神经元诱发放电活动的减弱，龙血竭对 WDR神经元诱发放电活动的抑制程度于加药后 10

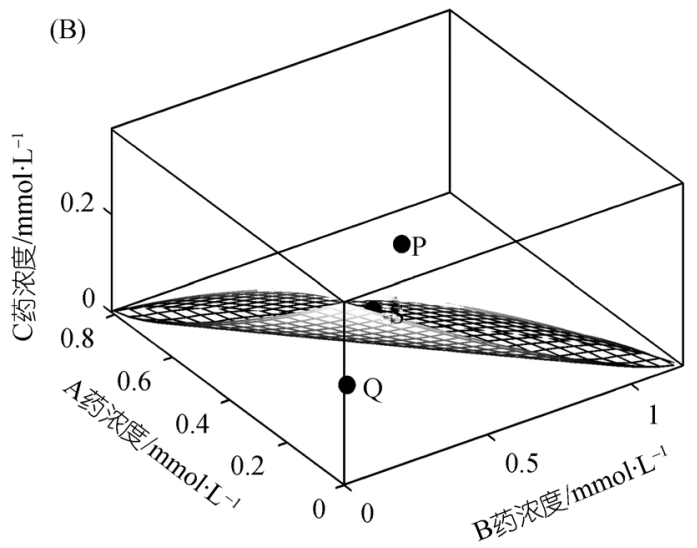

图 1 分析药物相互作用性质的相加等效图

(A) 二维坐标图上药物 $\mathrm{A}, \mathrm{B}$ 联合产生效应 $B_{i}$ 的 2 条相加等效线，这 2 条相加等效线与 2 个坐标轴的交点分别为 $\left(A_{i}, 0\right),\left(0, B_{i}\right) ; \mathrm{Q}^{\prime}, \mathrm{P}^{\prime}$ 点为 由原点发出的经过实验点 $\mathrm{Q}$ 的射线与 2 条等效线的 2 个交点，处于坐标图上不同位置的 $\mathrm{Q}, \mathrm{P}, \mathrm{S}$ 点分别表示药物 $\mathrm{A}, \mathrm{B}$ 之间相互作用的性 质为协同、拮抗和相加; (B) 三维坐标图上药物 $\mathrm{A}, \mathrm{B}, \mathrm{C}$ 联合产生效应 $B_{i}$ 的 3 个相加等效曲面, 这 3 个相加等效曲面与 3 个坐标轴的交点 分别为 $\left(A_{i}, 0,0\right),\left(0, B_{i}, 0\right),\left(0,0, C_{i}\right)$, 处于坐标图上不同位置的 $\mathrm{Q}, \mathrm{P}, \mathrm{S}$ 点分别表示药物 $\mathrm{A}, \mathrm{B}, \mathrm{C}$ 之间相互作用的性质为协同、拮抗和相加 
或 $15 \mathrm{~min}$ 时达到最大(图 2(A)和(B)), 之后 WDR 神经 元诱发放电活动有不同程度的恢复. 将龙血竭各浓 度组的效应与 ACSF 组的效应进行组间双因素 ANOVA 检验. 结果表明, $0.0005 \%$ 的龙血竭溶液 $(n=6$; $F=16.72, P<0.001), 0.005 \%$ 的龙血竭溶液 $(n=6$; $F=83.02, \quad P<0.001), \quad 0.05 \%$ 的龙血. 竭溶液 $(n=8$; $F=149.97, P<0.001), 2 \%$ 的龙血竭溶液 $(n=6 ; F=221.56$, $P<0.001)$ 和 $5 \%$ 的龙血竭溶液 $(n=6 ; F=189.26, P<0.001)$ 均对 WDR 神经元的诱发放电频率具有抑制作用.

龙血竭溶液对电刺激坐骨神经诱发的 WDR 神经 元放电频率具有浓度依赖的抑制作用(图 2(C)), $0.0005 \%, 0.005 \%, 0.05 \%$ 的龙血竭溶液对 WDR 神经 元诱发放电频率的最大抑制率 $(P<0.05)$ 分别为 $(9.78 \pm 1.51) \%,(19.66 \pm 3.48) \% ，(30.56 \pm 2.09) \%, 2 \%$ 和 $5 \%$ 的龙血竭溶液对 WDR 神经元诱发放电频率的最 大抑制率 $(P<0.01)$ 没有差别 $(P>0.05)$, 分别为 (46.17 \pm 1.57$) \%$ 和 $(46.91 \pm 2.19) \%$, 说明这 2 个抑制率 均已接近龙血竭抑制 WDR 神经元诱发放电频率的最 大效应. 以龙血竭对 WDR 神经元诱发放电频率的最 大抑制率为药物效应，绘制龙血竭的量效关系曲线， 用 Hill 方程(公式 2)拟合曲线, 得龙血竭的半数抑制 浓度为 $0.024 \%, 95 \%$ 的置信区间为 $(0.019 \% \sim 0.029 \%)$, Hill 系数为 $0.369,95 \%$ 的置信区间为 $(0.351 \sim 0.384)$.

\section{2 龙血竭的 3 种化学成分对电刺激坐骨神经诱 发的 WDR 神经元放电频率的影响}

与龙血竭相似, 剑叶龙血素 A、剑叶龙血素 B 和 龙血素 $\mathrm{B}$ 分别单独滴加至脊髓表面后, 于加药后 2 $\min$ 时刻即可观察到 WDR 神经元诱发放电活动的减 弱, 并于加药后 10 或 $15 \mathrm{~min}$ 时减至最弱(图 3(A) (C)), 之后有不同程度的恢复. 将 3 种化学成分各浓 度组的效应与 ACSF 组的效应进行组间双因素 ANOVA 检验, 3 种化学成分对 WDR 神经元的诱发放 电频率具有不同程度的抑制作用(每种药物每个浓度 下 $n=6, P<0.001)$. 与 $0.05 \%$ 龙血竭溶液浓度相对应的 剑叶龙血素 A、剑叶龙血素 B 和龙血素 B 3 种溶液对 WDR 神经元诱发放电频率的最大抑制率分别为 (20.37 \pm 3.06$) \%$ ，(18.36 \pm 3.36$) \%$ 和(18.24 \pm 3.27$) \%$. 将 3
种化学成分各浓度组的效应与 $0.05 \%$ 龙血竭溶液的 效应进行组间双因素 ANOVA 检验发现, 3 种化学成 分单独作用对 WDR 神经元诱发放电频率的抑制效应 与 $0.05 \%$ 龙血竭溶液的抑制效应均存在差异 $(P<0.05)$.

以加药后 3 种化学成分对 WDR 神经元诱发放电 频率的最大抑制率为药物效应，绘制 3 种化学成分单 独作用的量效关系曲线，用 Hill 方程(公式 2)拟合曲 线(图 3(D) (F)). 剑叶龙血素 $\mathrm{A}$ 半数抑制浓度为 0.953 $\mathrm{mmol} / \mathrm{L}, 95 \%$ 置信区间为 $(0.894 \sim 1.027) \mathrm{mmol} / \mathrm{L}$, Hill 系数为 $0.552,95 \%$ 置信区间为 $(0.516 \sim 0.581)$; 剑叶龙 血素 B 半数抑制浓度为 $0.575 \mathrm{mmol} / \mathrm{L}, 95 \%$ 置信区间 为 $(0.492 \sim 0.652) \mathrm{mmol} / \mathrm{L}$, Hill 系数为 $0.60,95 \%$ 置信区 间为 $(0.571 \sim 0.638)$; 龙血素 $\mathrm{B}$ 半数抑制浓度为 0.242 $\mathrm{mmol} / \mathrm{L}, 95 \%$ 的置信区间为 $(0.217 \sim 0.266) \mathrm{mmol} / \mathrm{L}$, Hill 系数为 $0.481,95 \%$ 置信区间为 $(0.425 \sim 0.527)$, 可 明显看出 Hill 系数之间具有统计学上的差异. 10 $\mathrm{mmol} / \mathrm{L}$ 的剑叶龙血素 A、剑叶龙血素 B 和龙血素 B 单独作用对 WDR 神经元诱发放电频率的最大抑制率 分别为 $(42.19 \pm 2.15) \%,(45.31 \pm 2.87) \%$ 和 $(47.15 \pm$ $1.91) \%$, 这些抑制率之间没有差别 $(P>0.05)$. 由于药 品浓度的数量级已经很高, 这些抑制率应已接近这 3 种成分抑制 WDR 神经元诱发放电频率的最大效应, 故可以认为剑叶龙血素 A、剑叶龙血素 $\mathrm{B}$ 和龙血素 B 所能产生的最大效应 $\left(E_{\text {max }}\right)$ 相等.

\subsection{3 种化学成分的各种组合对电刺激坐骨神经 诱发的 WDR 神经元放电频率的影响}

3 种化学成分的各种组合对电刺激坐骨神经诱 发的 WDR 神经元放电频率也具有不同程度的抑制作 用(组合 $1,2,3$ 的 $n=6$, 组合 4 的 $n=8$, 每种组合的药 理效应均与 ACSF 的药理效应进行组间双因素 ANOVA 检验, $P<0.001)$, 抑制效应均在加药后 $10 \mathrm{~min}$ 时刻达到最大(图 4(A)). 将 4 种组合的药理效应与 $0.05 \%$ 龙血竭溶液的药理效应进行组间双因素 ANOVA 检验发现，仅组合 4 对 WDR 神经元诱发放 电频率的抑制效应与 $0.05 \%$ 龙血竭溶液的抑制效应 不存在差异(表 3, 图 4(B)). 


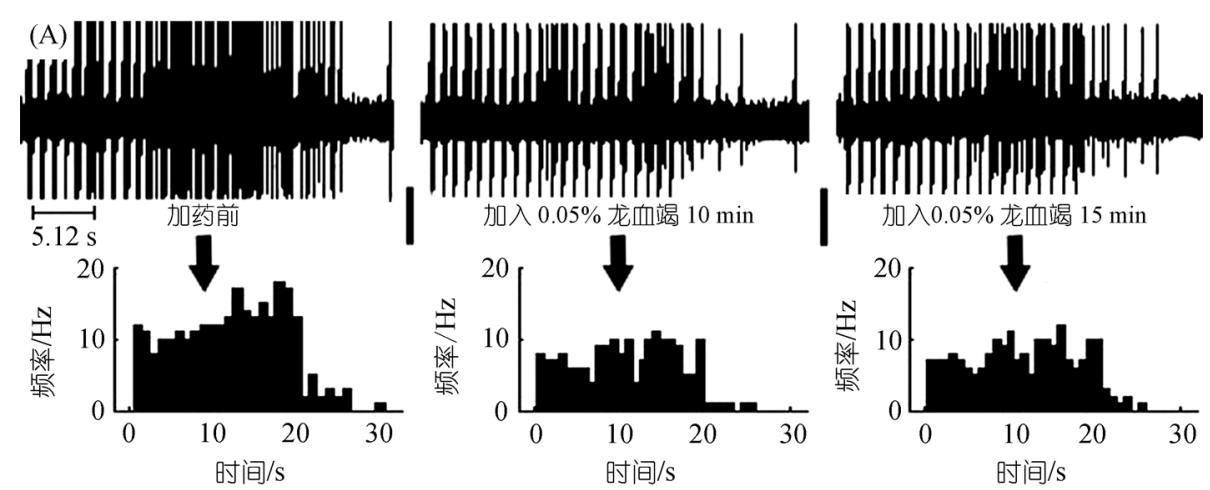

(B)
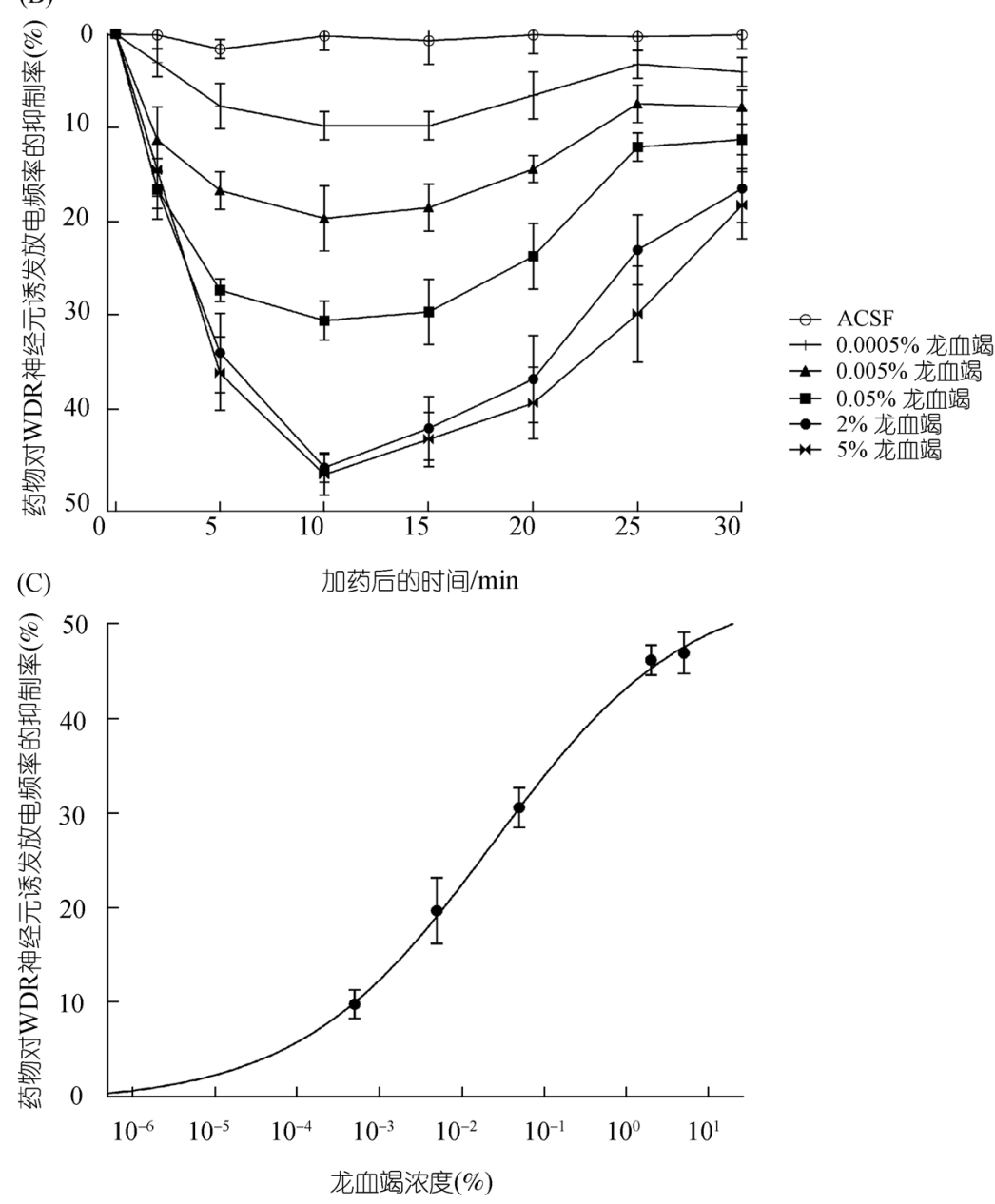

图 2 龙血竭对电刺激坐骨神经诱发的 WDR 神经元放电频率的影响

(A) $0.05 \%$ 的龙血竭对电刺激坐骨神经诱发的 WDR 神经元放电活动的影响, 图的上半部分为 $0.05 \%$ 的龙血竭加药前后电刺激坐骨神经诱发的 WDR 神经元的放电活动记录, 图的下半部分为加药前后 WDR 神经元诱发放电频率的直方图; (B) 以 ACSF 为对照, 不同浓度的龙血竭在 加药后的不同时刻对电刺激坐骨神经唀发的 WDR 神经元放电频率的抑制率; (C) 龙血竭抑制 WDR 神经元诱发放电频率的量效关系曲线

2.4 龙血竭 3 种化学成分之间相互作用性质的判定 基于方程(4), (5)判定剑叶龙血素 A、剑叶龙血素 $\mathrm{B}$ 和龙血素 $\mathrm{B}$ 两两相互作用的性质，基于方程(6 8)
判定这 3 种化学成分相互作用的性质. 将剑叶龙血素 A、剑叶龙血素 $\mathrm{B}$ 和龙血素 $\mathrm{B}$ 的相关数据代入方程 (4 8), 所计算的实验点 $Q_{1} \sim Q_{4}$ 与其各自所对应的理 

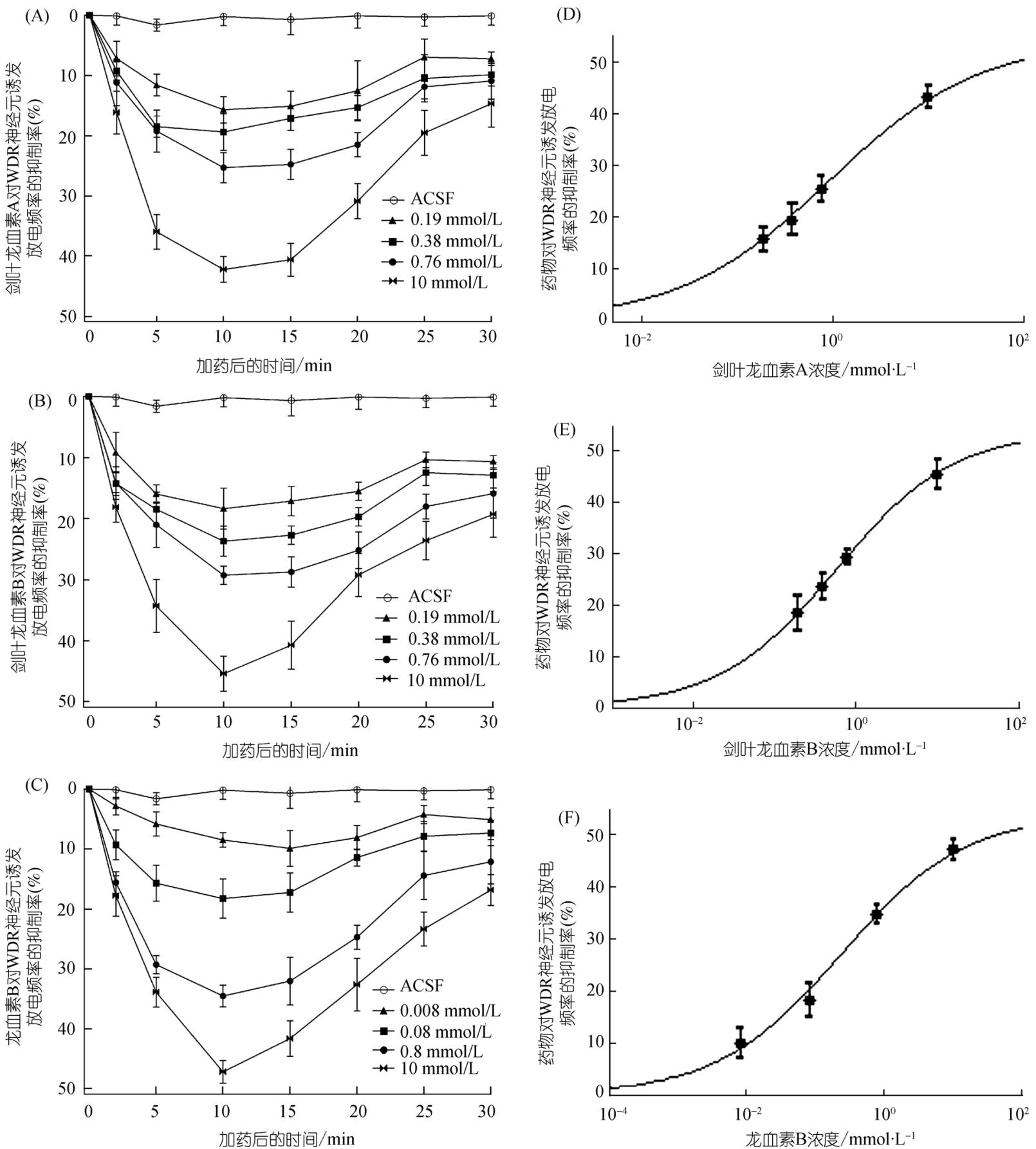

图 3 龙血竭的 3 种化学成分对电刺激坐骨神经诱发的 WDR 神经元放电频率的影响

(A) (C) 以 ACSF 为对照, 不同浓度的剑叶龙血素 A、剑叶龙血素 B 和龙血素 B 在加药后的不同时刻对电刺激坐骨神经诱发的 WDR 神 经元放电频率的抑制率; (D) (F) 剑叶龙血素 A、剑叶龙血素 B 和龙血素 B 抑制 WDR 神经元诱发放电频率的量效关系曲线 
论可加点的相应坐标值详见表 4 和 5.

分别绘制 3 种化学成分两两联合作用产生效应 $E_{i}$ 的 6 条相加等效线和 3 种化学成分联合作用产生效 应 $E_{i}$ 的 3 个相加等效曲面, 并描出实验点 $\mathrm{Q}_{1} \sim \mathrm{Q}_{4}$ (图
5). 结果表明, 当 3 种化学成分两两联合作用时, 点 $Q_{1} \sim Q_{3}$ 的坐标值在统计上均分别大于它们各自所对 应的理论可加点的相应坐标值, $Q_{1} \sim Q_{3}$ 点均位于其相 应的 2 条等效线之上，表明剑叶龙血素 A、剑叶龙血

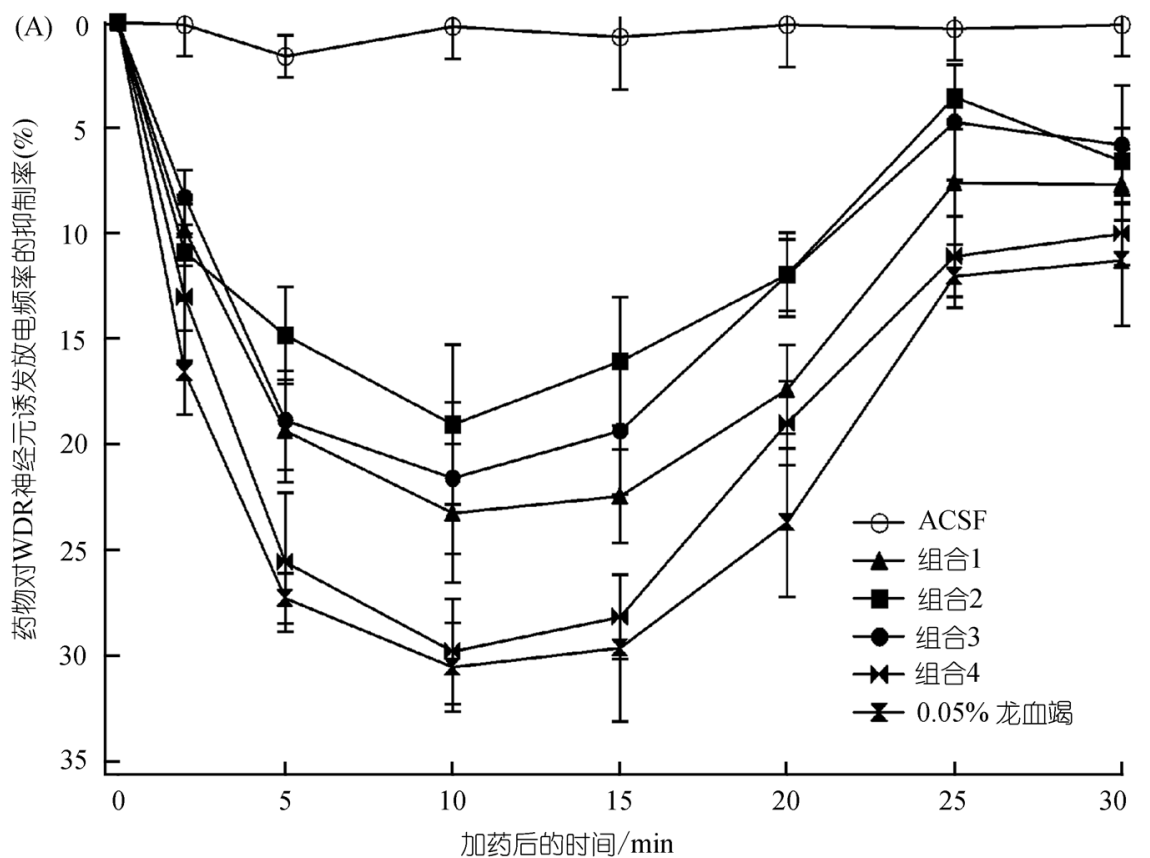

(B)
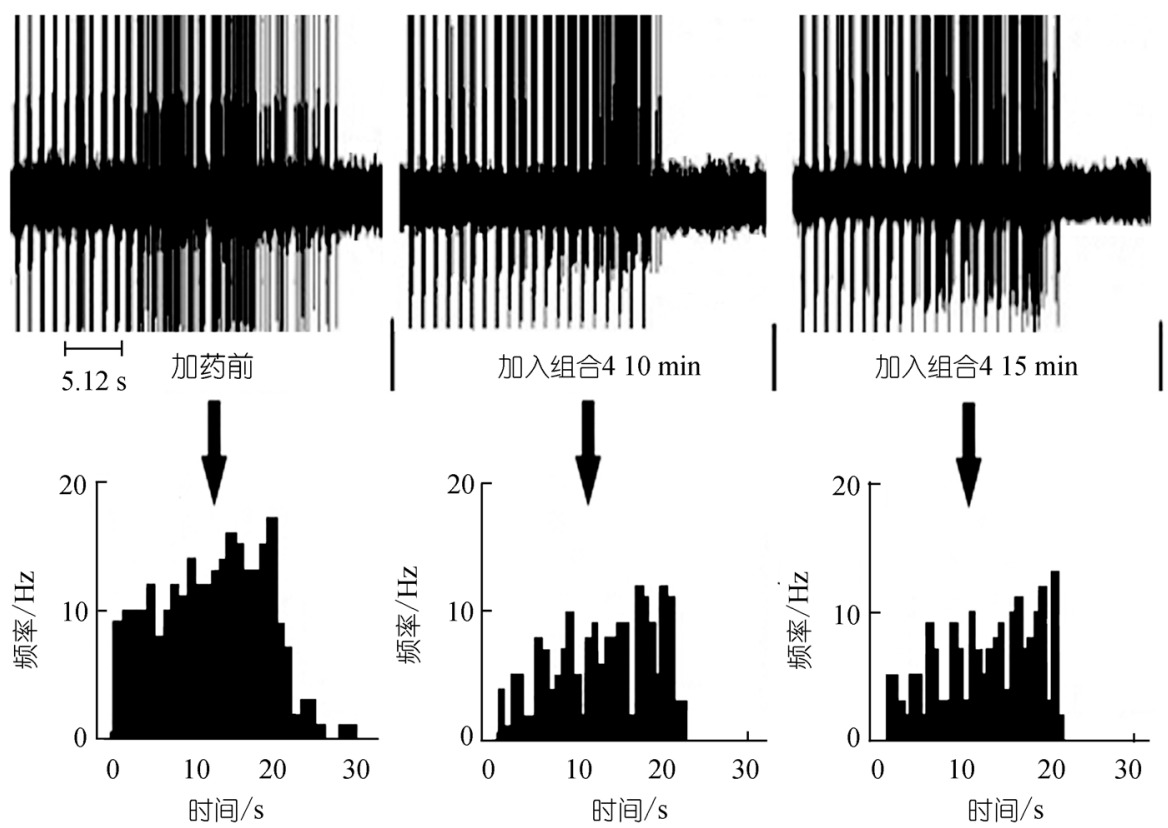

图 4 龙血竭 3 种化学成分的各种组合对 WDR 神经元诱发放电活动的影响

(A) 龙血竭 3 种化学成分的各种组合在加药后的不同时间对电刺激坐骨神经诱发的 WDR 神经元放电频率的影响; (B) 组合 4 对电刺激坐 骨神经诱发的 WDR 神经元放电活动的影响; 图的上半部分为组合 4 加药前后电刺激坐骨神经诱发的 WDR 神经元的放电活动记录, 图的 下半部分为加入组合 4 前后 WDR 神经元诱发放电频率的直方图 
素 B 和龙血素 B 在两两联合抑制 WDR 神经元诱发放 电频率时均具有拮抗作用. 而当 3 种化学成分联合作 用时, 点 $\mathrm{Q}_{4}$ 的坐标值在统计上均小于其所对应的理 论可加点的相应坐标值, $Q_{4}$ 点位于所有等效曲面之下, 表明剑叶龙血素 A 、剑叶龙血素 B 和龙血素 B 在联 合抑制 WDR 神经元诱发放电频率时具有协同作用.

\section{3 讨论}

脊髓背角 $(\mathrm{SDH})$ 是痛觉信息传递和加工的初级 中枢. 来自 DRG等初级感觉神经元的外周伤害性信 息，经过SDH神经元初步整合后，沿上行通路进入中 枢的高级部位. 在SDH神经元中, WDR神经元是唯一 接受感受伤害性刺激的 $A_{\delta}$ 和 $C$ 神经纤维、感受机械 性刺激的 $A_{\beta}$ 神经纤维等多种初级感觉传入的二级神
经元，对伤害性刺激和非伤害性刺激都发生反应. WDR 神经元对伤害性信息具有的编码和放大作用,

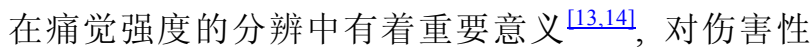
和非伤害性外周传入信息的汇聚作用可能也在脊髓 闸门控制机制的节段性调制痛觉信息中起重要作用 [15,16]，因而是痛觉传导的一个关键部位. 细胞外微电 极记录实验结果表明，龙血竭对电刺激坐骨神经诱 发的WDR神经元放电频率具有浓度依赖的抑制作用, $0.05 \%$ 的龙血竭溶液对WDR 神经元诱发放电频率的 最大抑制率为 $(30.56 \pm 2.09) \%$ ，说明龙血竭能在一定 程度上抑制WDR神经元对外周伤害性刺激的反应， 降低WDR神经元的兴奋性, 这可能是龙血竭产生镇 痛作用的原因之一。

在 WDR 神经元和 $\mathrm{DRG}$ 神经元上均分布着属于

表 3 龙血竭与其 3 种化学成分的各种组合的药理效应比较

\begin{tabular}{|c|c|c|c|c|c|}
\hline \multirow[t]{2}{*}{ 药物 } & \multicolumn{3}{|c|}{$\begin{array}{l}\text { 化学成分组合溶液中各种 } \\
\text { 化学成分的浓度 } / \mathrm{mmol} \cdot \mathrm{L}^{-1}\end{array}$} & \multirow{2}{*}{$\begin{array}{l}\text { 加药后 } 10 \text { min 药物对 WDR 神 } \\
\text { 经元诱发放电频率的抑制率(\%) }\end{array}$} & \multirow{2}{*}{$\begin{array}{l}\text { 与 } 0.05 \% \text { 的龙血竭溶液组进行 } \\
\text { 组间双因素 ANOVA 检验的 } P \text { 值 }\end{array}$} \\
\hline & 剑叶龙血素 A & 剑叶龙血素 B & 龙血素 B & & \\
\hline 组合 1 & 0.38 & 0.19 & 0 & $23.25 \pm 3.30$ & $P=0.001<0.01$ \\
\hline 组合 2 & 0.38 & 0 & 0.08 & $19.06 \pm 3.78$ & $P=0.001<0.01$ \\
\hline 组合 3 & 0 & 0.19 & 0.08 & $21.60 \pm 2.39$ & $P=0.001<0.01$ \\
\hline 组合 4 & 0.38 & 0.19 & 0.08 & $29.79 \pm 2.51$ & $P=0.414>0.05$ \\
\hline
\end{tabular}

\section{表 4 实验点 $Q_{1}, Q_{2}$ 与其各自所对应的理论可加点的相应坐标值}

\begin{tabular}{|c|c|c|c|c|c|c|}
\hline \multirow[b]{2}{*}{ 坐标轴 } & \multicolumn{3}{|c|}{ 组合 1 联合作用效应 $E_{i}=23.25$} & \multicolumn{3}{|c|}{ 组合 2 联合作用效应 $E_{i}=19.06$} \\
\hline & $\begin{array}{l}\text { 点 } Q_{1} \\
\text { 坐标值 }\end{array}$ & $\begin{array}{r}\mathrm{Q}_{1} \text { 对应的理论 } \\
\text { 及其 } 95 \%\end{array}$ & $\begin{array}{l}\text { 加点的坐标值 } \\
\text { 昌信区间 }\end{array}$ & $\begin{array}{l}\text { 点 } Q_{2} \\
\text { 坐标值 }\end{array}$ & $\begin{array}{r}\mathrm{Q}_{2} \text { 对应的理 } \\
\text { 及其 } 95\end{array}$ & $\begin{array}{l}\text { 加点的坐标值 } \\
\text { 信区间 }\end{array}$ \\
\hline $\begin{array}{c}\text { 剑叶龙血素 A 浓度 } \\
/ \mathrm{mmol} \cdot \mathrm{L}^{-1}\end{array}$ & 0.38 & $\begin{array}{c}0.3111 \\
(0.2877 \sim 0.3290)\end{array}$ & $\begin{array}{c}0.3294 \\
(0.3059 \sim 0.3473)\end{array}$ & 0.38 & $\begin{array}{c}0.1527 \\
(0.1344 \sim 0.1673)\end{array}$ & $\begin{array}{c}0.1748 \\
(0.1553 \sim 0.1902)\end{array}$ \\
\hline $\begin{array}{c}\text { 剑叶龙血素 B 浓度 } \\
\qquad / \mathrm{mmol}^{-} \cdot \mathrm{L}^{-1}\end{array}$ & 0.19 & $\begin{array}{c}0.1555 \\
(0.1455 \sim 0.1681)\end{array}$ & $\begin{array}{c}0.1647 \\
(0.1546 \sim 0.1774)\end{array}$ & / & / & l \\
\hline $\begin{array}{c}\text { 龙血素 B 浓度 } \\
/ \mathrm{mmol} \cdot \mathrm{L}^{-1}\end{array}$ & / & l & / & 0.08 & $\begin{array}{c}0.0351 \\
(0.0272 \sim 0.0415)\end{array}$ & $\begin{array}{c}0.0386 \\
(0.0303 \sim 0.0453)\end{array}$ \\
\hline
\end{tabular}

\section{表 5 实验点 $Q_{3}, Q_{4}$ 与其各自所对应的理论可加点的相应坐标值}

\begin{tabular}{|c|c|c|c|c|c|c|c|}
\hline \multirow[b]{2}{*}{ 坐标轴 } & \multicolumn{3}{|c|}{ 组合 3 联合作用效应 $E_{i}=21.60$} & \multicolumn{4}{|c|}{ 组合 4 联合作用效应 $E_{i}=29.79$} \\
\hline & $\begin{array}{l}\text { 点 } Q_{3} \\
\text { 坐标值 }\end{array}$ & $\begin{array}{r}\mathrm{Q}_{3} \text { 对应的理论 } \\
\text { 及其 } 95 \%\end{array}$ & $\begin{array}{l}\text { 加点的坐标值 } \\
\text { 置信区间 }\end{array}$ & $\begin{array}{l}\text { 点 } \mathrm{Q}_{4} \\
\text { 坐标值 }\end{array}$ & $\mathrm{Q}_{4}$ 又 & $\begin{array}{l}\text { 的理论可加点的 } \\
\text { 及其 } 95 \% \text { 置信区间 }\end{array}$ & 沶值 \\
\hline $\begin{array}{c}\text { 剑叶龙血素 } \mathrm{A} \text { 浓度 } \\
/ \mathrm{mmol} \cdot \mathrm{L}^{-1}\end{array}$ & I & / & / & 0.38 & $\begin{array}{c}0.5952 \\
(0.5760 \sim 0.6093)\end{array}$ & $\begin{array}{c}0.5152 \\
(0.4936 \sim 0.5313)\end{array}$ & $\begin{array}{c}0.4984 \\
(0.4764 \sim 0.5148)\end{array}$ \\
\hline $\begin{array}{c}\text { 剑叶龙血素 B 浓度 } \\
/ \mathrm{mmol} \cdot \mathrm{L}^{-1}\end{array}$ & 0.19 & $\begin{array}{c}0.1286 \\
(0.1192 \sim 0.1406)\end{array}$ & $\begin{array}{c}0.1479 \\
(0.1380 \sim 0.1604)\end{array}$ & 0.19 & $\begin{array}{c}0.2976 \\
(0.2878 \sim 0.3095)\end{array}$ & $\begin{array}{c}0.2576 \\
(0.2473 \sim 0.2702)\end{array}$ & $\begin{array}{c}0.2492 \\
(0.2388 \sim 0.2619)\end{array}$ \\
\hline $\begin{array}{l}\text { 龙血素 B 浓度 } \\
/ \mathrm{mmol} \cdot \mathrm{L}^{-1}\end{array}$ & 0.08 & $\begin{array}{c}0.0524 \\
(0.0428 \sim 0.0599)\end{array}$ & $\begin{array}{c}0.0637 \\
(0.0534 \sim 0.0715)\end{array}$ & 0.08 & $\begin{array}{c}0.1253 \\
(0.1149 \sim 0.1327)\end{array}$ & $\begin{array}{c}0.1085 \\
(0.0976 \sim 0.1163)\end{array}$ & $\begin{array}{c}0.1049 \\
(0.0939 \sim 0.1128)\end{array}$ \\
\hline
\end{tabular}


TTX-S 钠离子通道的Nav1.3 通道亚型 ${ }^{[17]}$. 脊神经顿 挫伤后四周会发现 SDH 神经元的Nav1.3 表达上调, 鞘内注射针对Nav1.3 的反义寡核苷酸可减少SDH神 经元的过度兴奋 ${ }^{[18]}$. 由于龙血竭对 DRG 神经元 TTX-S钠离子通道电流具有调制作用 ${ }^{[3]}$, 在脊神经结 扎和脊神经顿挫伤后, 成年大鼠DRG 神经元上的 Nav1.3mRNA 和蛋白表达也均上调 ${ }^{[19]}$, 因而龙血竭 很可能通过调制Nav1.3 通道亚型而降低WDR神经元 的兴奋性，抑制WDR 神经元对外周伤害性刺激的反 应. 此外, 在小直径DRG神经元和 SDH的 I, II 和X层 均分布有电压门控性钠离子通道的 $\beta_{3}$ 亚单位. Shah 等人 ${ }^{[20]}$ 发现，在坐骨神经慢性压迫模型中，小直径 $\mathrm{DRG}$ 神经元上 $\beta_{3}$ mRNA的表达显著增加. 而将Nav1.3 的mRNA和 $\beta_{3}$ 亚单位的mRNA在HEK293 细胞上合并 表达，可形成一种新的具有 TTX-R钠离子通道特性 的电压门控性钠离子通道 ${ }^{[21]}$. 由于龙血竭对 DRG神
经元TTX-R钠离子通道电流亦具有调节作用 ${ }^{[4]}$, 因而 其可能对 $\mathrm{SDH}$ 上的 $\beta_{3}$ 亚单位也具有调制作用, 并通 过SDH各层神经元之间的复杂相互作用，抑制WDR 神经元对外周伤害性刺激的反应.

以龙血竭抑制 WDR 神经元诱发放电频率的药 理效应为参照, 通过龙血竭 3 种成分以及它们各种组 合的药理效应与龙血竭药理效应的比较发现, 虽然 龙血竭的 3 种化学成分剑叶龙血素 A、剑叶龙血素 $\mathrm{B}$ 和龙血素 B 均对 WDR 神经元诱发放电有不同程度 的抑制作用，且抑制作用呈浓度依赖关系，但却没有 一种成分能够在其剂量与 $0.05 \%$ 龙血竭所含这些成 分的量相关联时，产生与 $0.05 \%$ 龙血竭相类似的抑制 效应, 因而这 3 种化学成分均是龙血竭抑制 WDR 神 经元诱发放电的有效成分，而非药效物质. 在按照 3 种成分各自在龙血竭提取终产物中的百分比含量配 制的组合溶液中，仅剑叶龙血素 A、剑叶龙血素 B 和
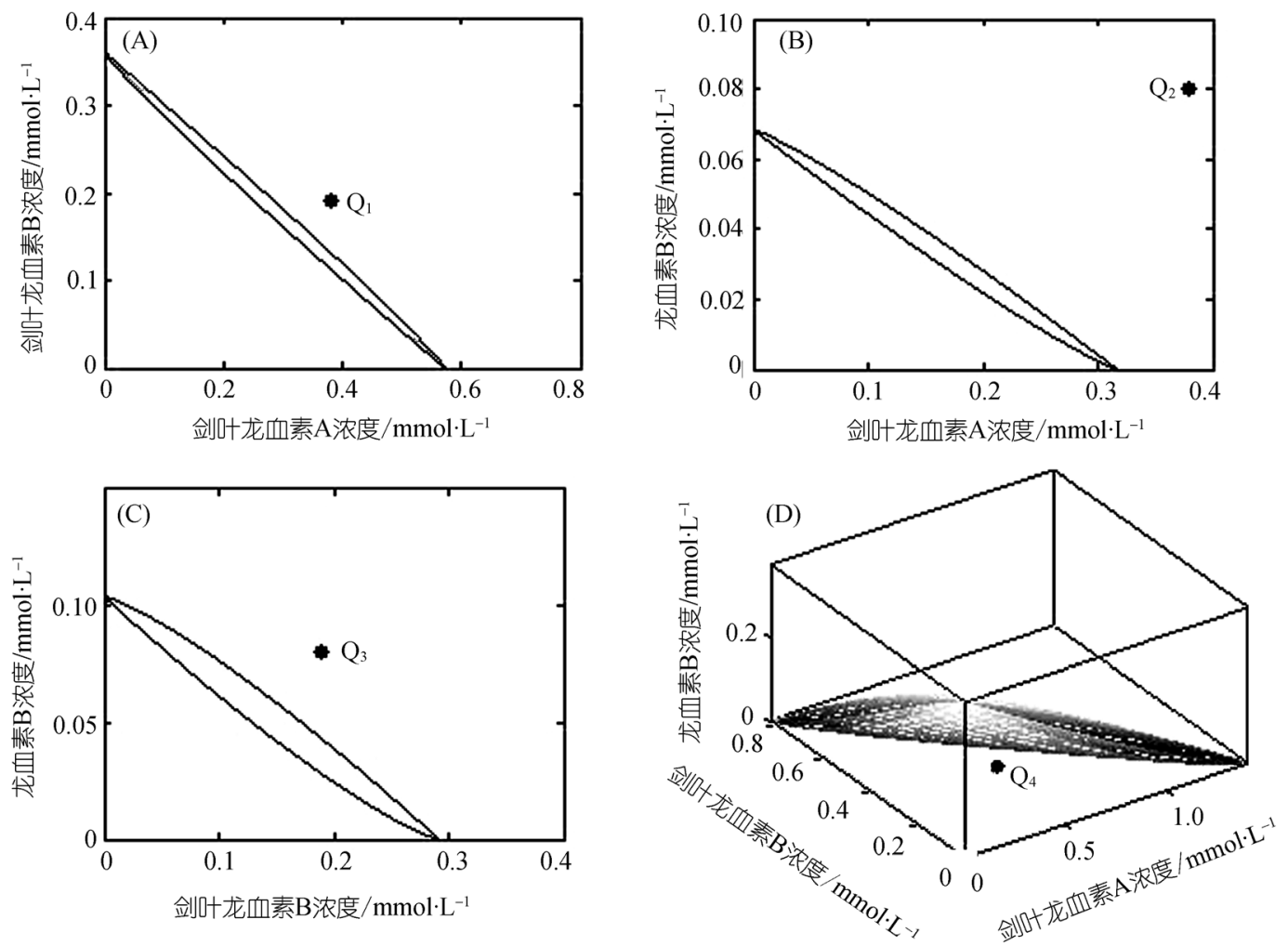

图 5 龙血竭的 3 种化学成分在不同组合方式时的相加等效图

(A) 剑叶龙血素 $\mathrm{A}$ 与剑叶龙血素 $\mathrm{B}$ 联合作用时的相加等效线与 $\mathrm{Q}_{1}$ 点的位置关系; (B) 剑叶龙血素 $\mathrm{A}$ 与龙血素 $\mathrm{B}$ 联合作用时的相加等效 线与 $Q_{2}$ 点的位置关系; (C) 剑叶龙血素 $B$ 与龙血素 $B$ 联合作用时的相加等效线与 $Q_{3}$ 点的位置关系; (D)剑叶龙血素 $A$ 、剑叶龙血素 $B$ 与 龙血素 B 联合作用时的相加等效曲面与 $\mathrm{Q}_{4}$ 点的位置关系 
龙血素B的组合溶液能产生类似于 $0.05 \%$ 龙血竭溶液 的对WDR神经元诱发放电的抑制效应，根据传统药 物药效物质的操作型定义 ${ }^{[4]}$, 剑叶龙血素A、剑叶龙 血素B和龙血素 $\mathrm{B}$ 的组合才应是龙血竭抑制伤害性刺 激诱发的WDR神经元放电反应，在脊髓水平调控痛 觉信息传递和加工的药效物质.

与只用单个参数的模型来做评估相比较, 等效 图分析法在实验影响因素较多(如在体动物实验)的情 况下更为合适，因此采用该方法评估了 3 种化学成分 的各种组合抑制WDR神经元诱发放电活动的相互作 用性质。等效图分析结果表明，剑叶龙血素A、剑叶 龙血素B和龙血素B在联合抑制WDR神经元诱发放电 频率时具有协同作用，但 3 种成分在两两联合抑制 WDR 神经元诱发放电频率时却均具有拮抗作用. 除 了剑叶龙血素B和龙血素B联合调制DRG细胞TTX-R 钠离子电流的相互作用为添加之外, 3 种成分的各种 组合在抑制WDR神经元诱发放电活动和调制DRG细 胞TTX-R钠离子电流时的相互作用性质 ${ }^{[4]}$ 均一致. 这 些相互作用性质之间的一致性说明龙血竭的 3 种化 学成分抑制WDR神经元诱发放电活动的机制与其调 节钠离子通道电流密切相关, 差异性则说明 SDH各
层神经元之间的相互作用、闸门控制 ${ }^{[15]}$ 等更复杂的机 制也必然参与其中.

在现代药物研发中, 传统药物是发现和分离新 的药物的丰富源泉, 反向药理学 ${ }^{[22,23]}$ (reverse pharmacology) 是再发现的范例. 遵循反向药理学的研究思 路, 将临床用药和草药验方的线索和观测性结果延 伸到探索性研究中, 进行体内、外实验, 并结合传统 药物药效物质的操作型定义 ${ }^{[4]}$ 来解决如何寻找和判 别能(近似)替代产生传统药物本身的药理效应且结构 清楚的化学成分或化学成分的组合这一问题, 系统 地开展了传统药物龙血竭镇痛效应药理机制和相应 药效物质的研究. 以前的药理研究大多将龙血竭的 镇痛效应归纳为“消炎镇痛” ”2], 膜片钳实验研究则发 现龙血竭对外周初级感觉神经元电压门控性钠通道 具有调制作用 ${ }^{[3,4]}$, 在体实验的研究结果表明, 龙血 竭也能够从脊髓水平调节痛觉信息的传递和加工, 说明龙血竭能从多层次、多途径干预痛觉信息的发生 和传导, 产生镇痛效应. 龙血竭镇痛药效物质的确定 和其化学成分相互作用性质的判定结果也体现了传 统药物的药理效应往往是由多种成分的分子组合所 产生的. 低剂量的几种化学成分联合起来协同产生 较高的药理效应, 似乎是传统药物的独特之处.

\section{参考文献}

1 赵远, 王曙光, 郭世民, 等. 龙血竭胶囊的大鼠长期毒性研究. 中国中药杂志, 2007, 28(4): 33-35

2 曹广军, 张静泽, 胡迎庆, 等. 不同工艺提取龙血竭的抗炎镇痛止血作用的比较. 天津药学, 2005, 17(3): 3-4

3 刘向明, 陈素, 尹世金, 等. 血竭及其成分龙血素 B 对背根神经节细胞河豚毒素敏感型钠通道电流的影响. 中国科学 C 辑: 生命科学, 2004, 34(1): 80-87

4 刘向明, 陈素, 张玉霞, 等. 血竭对背根神经节细胞河豚毒素不敏感型钠电流的调制及其药效物质的确定. 中国科学 C 辑: 生命科学, 2006, 36(1): 76-85

5 Almeida T F, Roizenblatt S, Tufik S. Afferent pain pathways: a neuroanatomical review. Brain Res, 2004, 1000: 40-56 [DOI]

6 Yu L C, Zheng E M, Lundeberg T. Calcitonin gene-related peptide 8-37 inhibits the evoked discharge frequency of wide dynamic range neurons in dorsal horn of the spinal cord in rats. Regul Pept, 1999, 83(1): 21-24 [DOI]

7 Liu F Y, Xing G G, Qu X X, et al. Roles of 5-HT receptor subtypes in the inhibitory effects of 5-HT on C-fiber responses of spinal wide dynamic range neurons in rats. J Pharmacol Exp Ther, 2007, 321(3): 1046-1053 [DOI]

8 Berenbaum M C. What is synergy? Pharmacology Reviews, 1989, 41: 93-141

9 Loewe S, Muischnek H. Effect of combinations: mathematical basis of the problem. Arch Exp Pathol Pharmakol, 1926, 114: 313326 [DOI]

10 Tallarida R J. An overview of drug combination analysis with isobolograms(Perspectives in Pharmacology). J Pharmacol Exp Ther, 2006, 319: $1-7 \underline{\text { DOI] }}$

11 Tallarida R J. Interactions between drugs and occupied receptors. Pharmacol Ther, 2007, 113: 197—209 [DOD]

12 Urch C E, Dickenson A H. In vivo single unit extracellular recordings from spinal cord neurons of rats. Brain Res Protoc, 2003, 12(1): $26-34 \underline{[\mathrm{DOI}]}$ 
13 Coghill R C, Mayer D J, Price D D. Wide dynamic range but not nociceptive-specific neurons encode multidimensional features of prolonged repetitive heat pain. J Neurophysiol, 1993, 69: 703-716

14 Vahle-Hinz C, Detsch O. What can in vivo electrophysiology in animal models tell us about mechanisms of anaesthesia? Br J Anaesth, 2002, 89(1): 123-142[DOI]

15 Melzak R, Wall P D. Pain mechanisms: a new theory. Science, 1965, 150: 971 — 979[DOI]

16 Melzack R. From the gate to the neuromatrix. Pain, 1999, 6: 121-126 [DOI]

17 Nobukuni O, Yoshiaki O. Molecular diversity of structure and function of the voltage-gated $\mathrm{Na}^{+}$Channels. Jpn J Pharmacol, 2002, 88: $365-377 \underline{[\mathrm{DOI}]}$

18 Hains B C, Saab C Y, Waxman S G. Changes in electrophysiological properties and sodium channel Nav1.3 expression in thalamic neurons after spinal cord injury. Brain, 2005, 128(10): 2359—2371[DOI]

19 Hains B C, Klein J P, Saab C Y, et al. Upregulation of sodium channel Nav1.3 and functional involvement in neuronal hyperexcitability associated with central neuropathic pain after spinal cord injury. J Neurosci, 2003, 23(26): 8881—8892

20 Shah B S, Stevens E B, Gonzalez M I, et al. $\beta 3$, a novel auxiliary subunit for the voltage-gated sodium channel, is expressed preferentially in sensory neurons and is upregulated in the chronic constriction injury model of neuropathic pain. J Neurosci, 2000, 12: 39853990

21 Cummins T R, Aglieco F, Renganathan M. Nav1.3 sodium channels: rapid repriming and slow closed-state inactivation display quantitative differences after expression in a mammalian cell line and in spinal sensory neurons. J Neurosci, 2001, 21(16): 5952-5961

22 Smith C. Drug discovery in reverse. Nature, 2004, 428(6979): 227[DOI]

23 Patwardhan B, Vaidya A D B, Chorghade M. Ayurveda and natural products drug discovery. Current Science, 2004, 86(6): 789-799 